Original Research Paper

\title{
Reduction of PAPR by Using Clipping and Filtering for Different Modulation Schemes
}

\author{
${ }^{1}$ Arun Kumar and ${ }^{2}$ Manisha Gupta \\ ${ }^{I}$ Department of ECE, JECRC University, Jaipur, India \\ ${ }^{2}$ Department of Physics, JECRC University, Jaipur, India
}

\author{
Article history \\ Received: 04-12-2015 \\ Revised: 11-02-2016 \\ Accepted: 13-02-2016 \\ Corresponding Author: \\ Arun Kumar, \\ Department of ECE, JECRC \\ University, Jaipur, India \\ Email: arun.kumar1986@live.com
}

\begin{abstract}
Orthogonal Frequency Division Multiplexing (OFDM) is one of the most advanced technologies for high speed data access in mobile communication. It's significantly increases the capacity, data-rate etc. but one of its disadvantage is high Peak Average Power Ratio (PAPR) which reduce the performance of transmitter amplifier. In this study, PAPR is reduced by using a clipping and filtering technique for different modulation schemes like Binary Phase Shift Keying (BPSK), Quadrature Phase Shift Keying (QPSK), Quadrature Amplitude Modulation (QAM-64) and Phase Shift Keying (PSK-64). Result shows that PAPR is significantly reduced as compared to conventional Clipping and Filtering Technique.
\end{abstract}

Keywords: OFDM, PAPR, Clipping and Filtering, Complementary Cumulative Distribution Function (CCDF)

\section{Introduction}

OFDM System has achieved a lot of attention among different modulation techniques because of its robustness nature to inter symbol interference. A large number of sub-channel results in Crest Factor which creates inefficiency in transmitter amplifier. A lot of techniques have been proposed in the past (Kumar and Gupta, $2015 a ; 2015 b)$. However, the simple way to reduce the PAPR is by clipping the high amplitude peaks that creates the spikes at the output. Some techniques clip the signal at the output of IFFT and some other techniques used a filter to reduced the out-band power but the design of filter and its computational is complex and expensive. Clipping and filtering produce a splattering and introduce a noise in the signal. However the degradation of efficiency in the system can be overcome by using an A/D (Analog to Digital) and D/A (Digital to Analog) quantizer (Kumar and Gupta, 2015c; Zolghadrasli and Ghamat, 2008). This technique efficiently removed the unwanted component of expanded spectrum, it reduces the out-band power radiation and also reduce the PAPR without the spectrum expansion. However some of its disadvantages are, it results in peak growth and its iterative signals takes a long time and it will also increase the complexity at the receiver side. The Block diagram of Clipping and Filtering is shown in below Fig. 1.

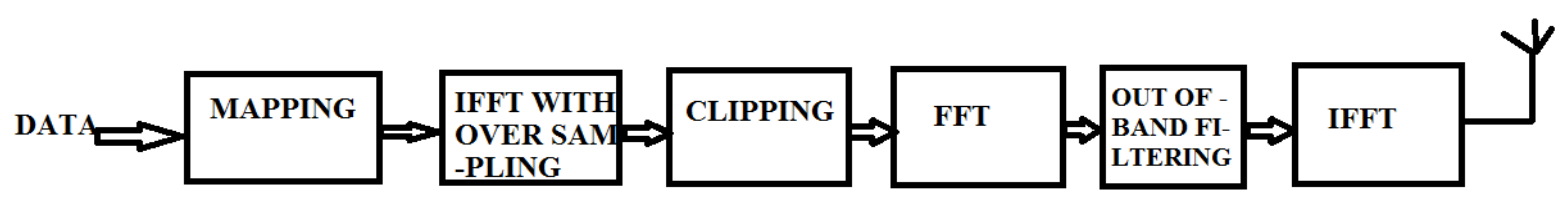

Fig. 1. Block diagram of clipping and filtering

Table 1. System model

\begin{tabular}{llll}
\hline BPSK & QPSK & QAM & PSK \\
\hline Enter the M-ary value: 2 & Enter the M-ary value: 4 & Enter the M-ary value: 64 & Enter the M-ary value: 64 \\
Enter the length of FFT: 2048 & Enter the length of FFT: 2048 & Enter the length of FFT: 2048 & Enter the length of FFT: 2048 \\
$\begin{array}{l}\text { Enter the number } \\
\text { of input symbols: } 2000\end{array}$ & Enter the number & Enter the number & Enter the number \\
Oversampling: 2 & Oversampling: 2 & of input symbols: 2000 & of input symbols: 2000 \\
\hline
\end{tabular}




\section{System Model}

In our design, we have considered a input symbols of 2000, the length of FFT is 2042 and the oversampling is done at the rate of 2. The PAPR reduction is done for BPSK, QPSK, QAM-64 and PSK-64. The data are passed through the IFFT mode. The System model is illustrated is the following Table 1.

\section{Simulated Results}

The simulated Graph is drawn between CCDF and SNR. It is seen that PAPR reduction is calculated for
BPSK, QPSK, PSK and QAM. It is also observed PAPR is reduced by using clipping and Filtering technique. The simulation Graph is repeated for modulation schemes such as BPSK, QPSK, 64-QAM and 64-PSK which are shown below. As shown in Fig. 2, the original PAPR of OFDM system was $16 \mathrm{~dB}$ but was reduced to $9.1 \mathrm{~dB}$ for BPSK. Figure 3, reduces the PAPR of OFDM system from $16 \mathrm{~dB}$ to $9.4 \mathrm{~dB}$ for QPSK. Figure 4 also shows the reduction PAPR of OFDM system from $16 \mathrm{~dB}$ but was reduced to $9.2 \mathrm{~dB}$ for QAM-64. Similarly, as shown in Fig. 5, the original PAPR of OFDM system was $16 \mathrm{~dB}$ but was reduced to $9.3 \mathrm{~dB}$ for PSK-64.

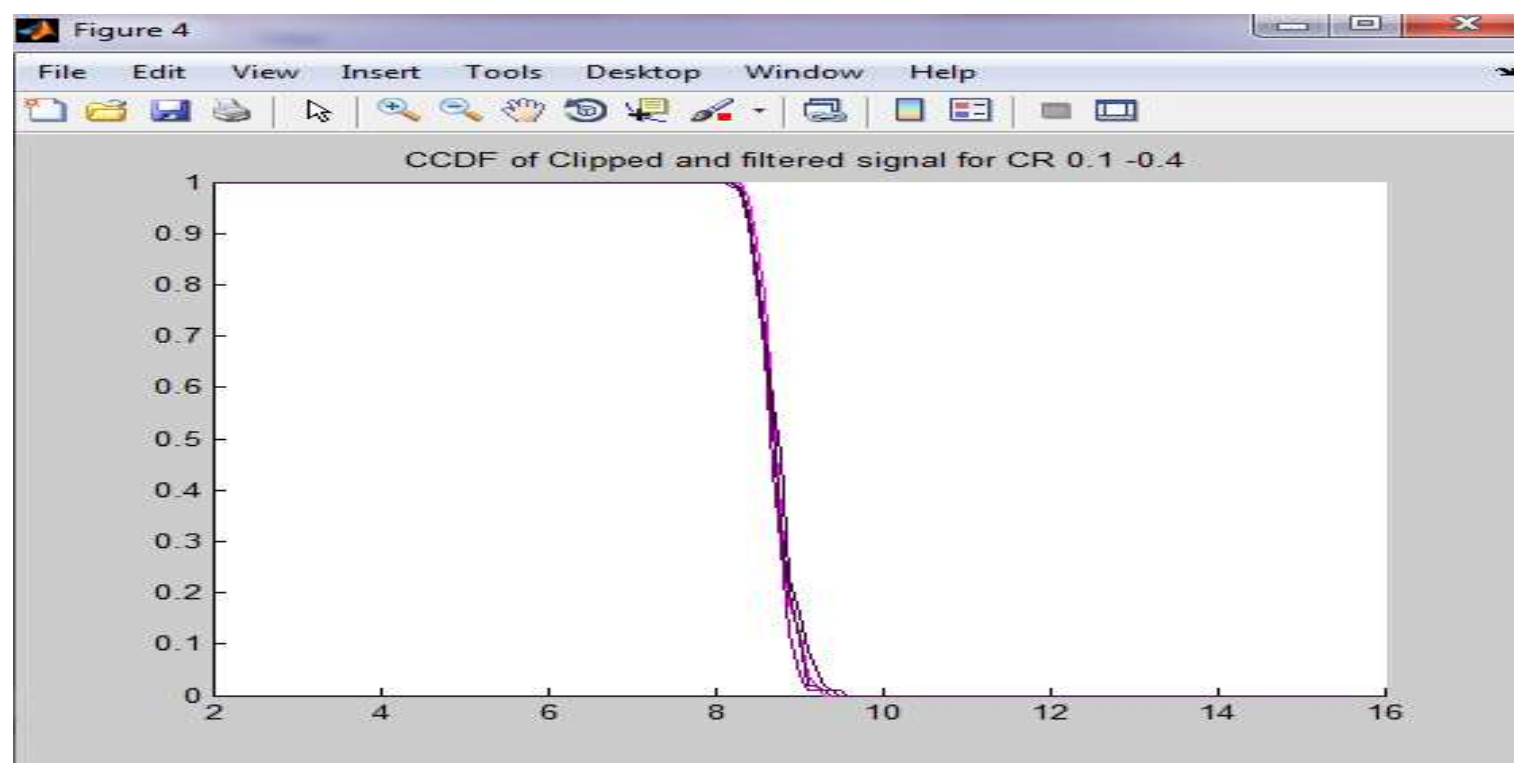

Fig. 2. PAPR reduction of OFDM using BPSK

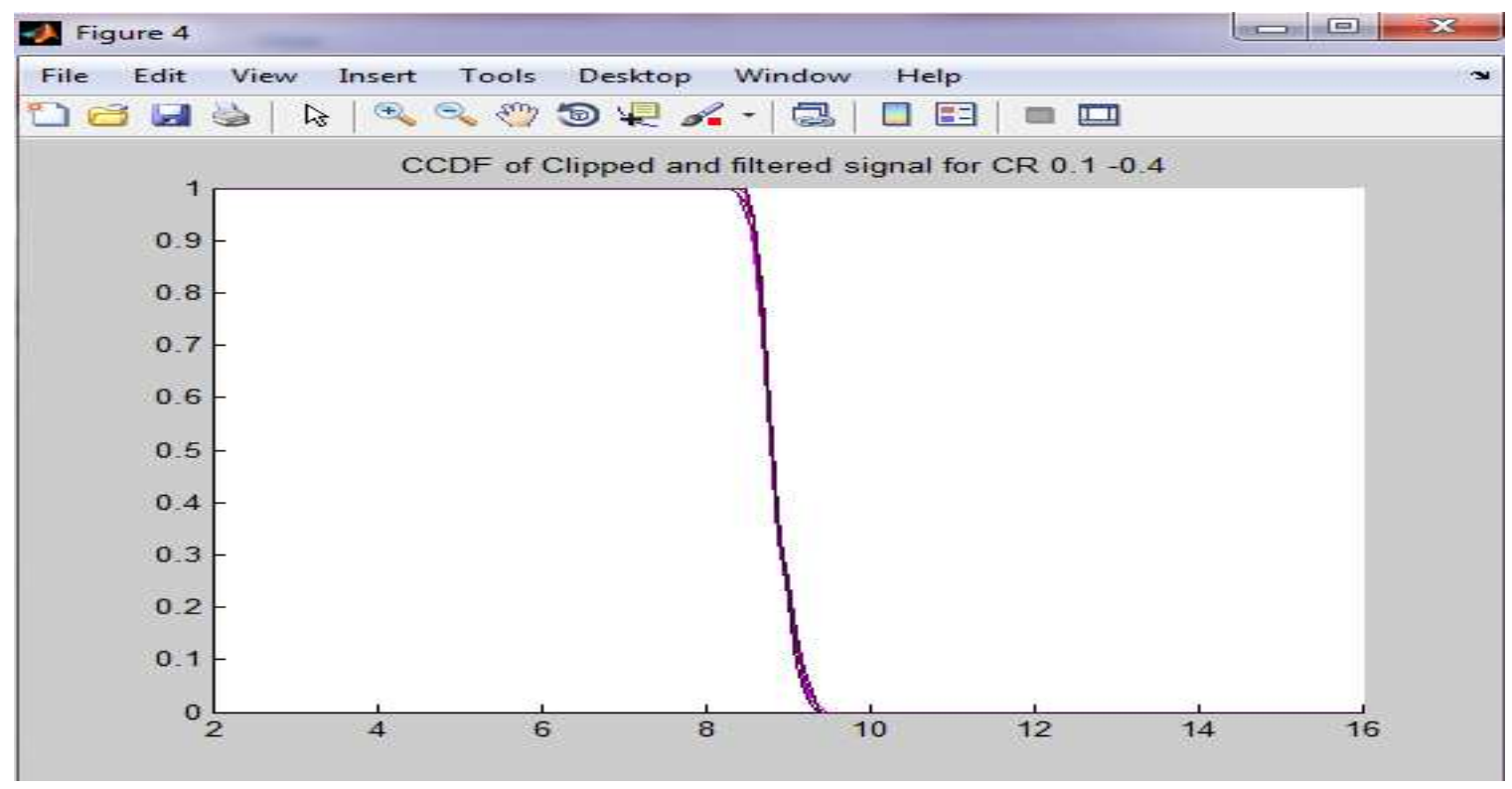

Fig. 3. PAPR reduction of OFDM using QPSK 


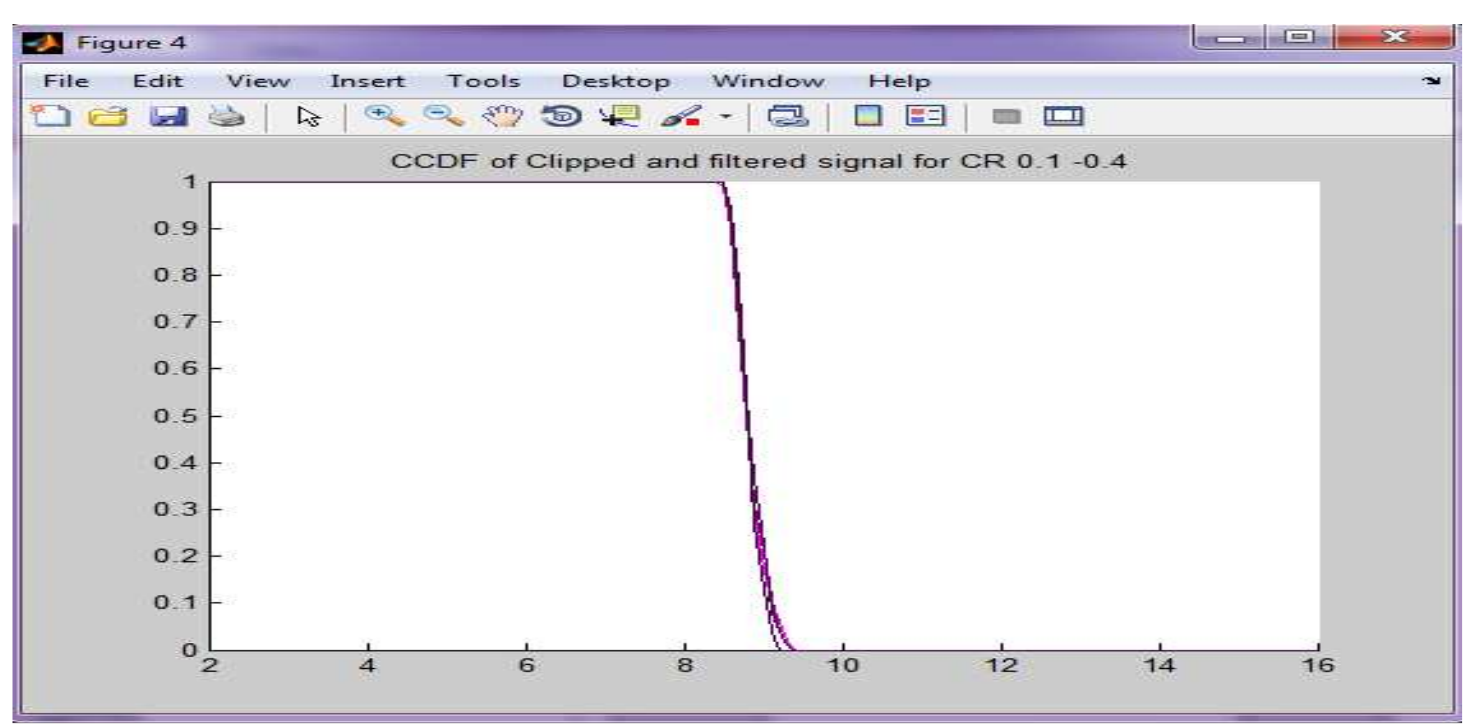

Fig. 4. PAPR reduction of OFDM using QAM-64

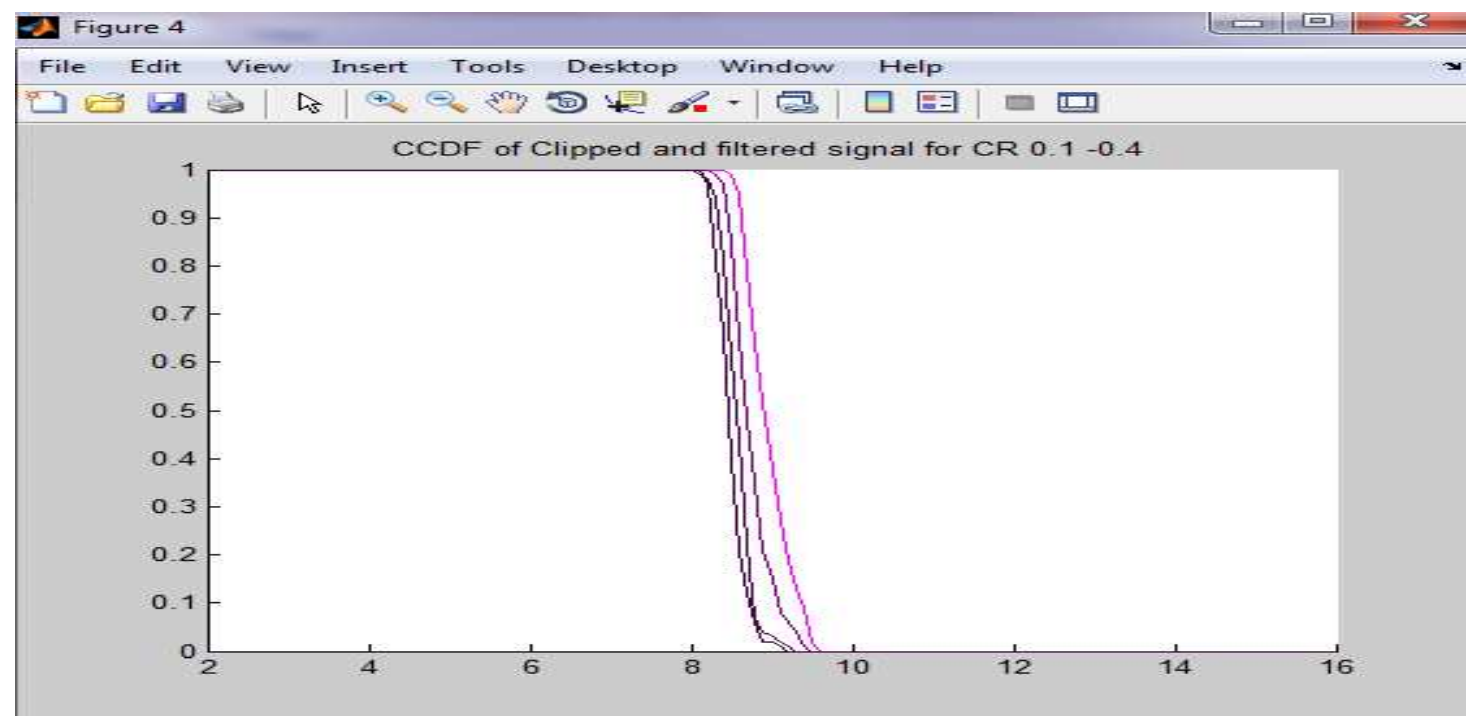

Fig. 5. PAPR reduction of OFDM using PSK-64

Table 2. Comparison of PAPR by using clipping and filtering technique Modulation

\begin{tabular}{lll}
$\begin{array}{l}\text { technique } \\
\text { PAPR }\end{array}$ & $\begin{array}{l}\text { Original } \\
\text { signal PAPR }\end{array}$ & $\begin{array}{l}\text { Clipping and } \\
\text { filtering }\end{array}$ \\
\hline BPSK & 16 & 9.1 \\
QPSK & 16 & 9.4 \\
64 QAM & 16 & 9.2 \\
64 PSK & 16 & 9.3 \\
\hline
\end{tabular}

\section{Conclusion}

There are many techniques that reduce the PAPR which has been proposed all of which have the potential to provide substantial reduction in PAPR at the cost of loss in data rate, transmit signal power increase, BER increase and computational complexity increase and so on. Here PAPR reduction based on Clipping and Filtering is done and following analyses is done which is given in below Table 2 .

\section{Acknowledgement}

Author's like to thanks to JECRC University for funding this work.

\section{Author's Contributions}

Arun Kumar: Have conducted the research and written the paper.

Manisha Gupta: Have design the research plan. 


\section{Ethics}

The work done in this paper is original and have not submitted anywhere else.

\section{References}

Kumar, A. and M. Gupta, 2015a. A review on OFDM and PAPR reduction techniques. Am. J. Eng. Applied Sci., 8: 202-209. DOI: 10.3844/ajeassp.2015.202.209

Kumar, A. and M. Gupta, 2015b. Design and comparison of MIMO OFDM for different transmission schemes. Electron. World Monthly, 121: 16-22.
Kumar, A. and M. Gupta, 2015c. Design of OFDM and PAPR reduction using clipping method: Artificial intelligence and network security. Desidoc. Drdo. Delhi, 1: 221-229.

Zolghadrasli and M.H. Ghamat, 2008. An overview of PAPR reduction techniques for multicarrier transmission and propose of new techniques for PAPR reduction. Iranian J. Electrical Comput. Eng., 7: 115-120. 